\title{
Microstructure and Thermomechanical Properties of Polyimide-Silica Nanocomposites
}

\author{
A. Al Arbash, Z. Ahmad, F. Al-Sagheer, and A. A. M. Ali \\ Department of Chemistry, Faculty of Science, Kuwait University, P.O. Box 5969, Safat 13060, Kuwait
}

Received 13 February 2006; Revised 15 June 2006; Accepted 13 November 2006

\begin{abstract}
Novel polyimide-silica nanocomposites with interphase chemical bonding have been prepared using the sol-gel process. The morphology, thermal and mechanical properties were studied as a function of silica content and compared with the similar composites having no interphase interaction. The polyimide precursors, polyamic acids (PAAs) with or without pendant hydroxyl groups were prepared from the reaction of pyromellitic dianhydride with a mixture of oxydianiline and 1,3 phenylenediamine or 2,4diminophenol in dimethylacetamide. The PAA with pendant hydroxyl groups was reacted with isocyanatopropyltriethoxysilane to produce alkoxy groups on the chain. The reinforcement of PAA matrices with or without alkoxy groups on the chain was carried out by mixing appropriate amount of tetraethoxysilane (TEOS) and carrying out its hydrolysis and condensation in a sol-gel process. Thin hybrid films were imidized by successive heating up to $300^{\circ} \mathrm{C}$. The presence of alkoxy groups on the polymer chain and their cocondensation with TEOS developed the silica network which was interconnected chemically with the polyimide matrix. SEM studies show a drastic decrease in the silica particle size in the chemically bonded system. Higher thermal stability and mechanical strength, improved transparency, and low values of thermal coefficient of expansion were observed in case of chemically bonded composites.
\end{abstract}

Copyright () $2006 \mathrm{~A}$. Al Arbash et al. This is an open access article distributed under the Creative Commons Attribution License, which permits unrestricted use, distribution, and reproduction in any medium, provided the original work is properly cited.

\section{INTRODUCTION}

Composites where nanoscale inclusions are imbedded within matrix material have attracted increasing research attention in recent years. Reviews on such composites using nanoclays $[1,2]$, nanotubes $[3,4]$, and inorganic networks [5-7] are available in literature. The inorganic networks are usually prepared by the sol-gel process $[7,8]$ to synergistically combine the properties of organic polymers (e.g., toughness, ductility, and processability) with that of ceramic materials (e.g., heat resistance, low thermal expansion, and retention of mechanical properties at high temperatures) $[9,10]$.

Polyimides (PIs) are extensively used in microelectronics and aerospace industries owing to their excellent thermal, mechanical, and dielectric properties [11]. However, PIs exhibit relatively high value of water absorption and the coefficient of thermal expansion, which can limit their application in the field of electronics. Composites from PIs and silica offering favorable properties of the both are therefore in great demand and further improvement in these can be achieved by bringing the dispersion of reinforced inorganic material to nanolevel in the matrix. The compatibility between PIs and silica generated in the sol-gel process using different tetraalkoxy silanes in the hybrids, however, is not as good as expected because of weak interactions between the pure organic and inorganic phases [12]. Tendency of the silica network to agglomerates into large particles at higher silica loading ultimately leads to phase separation. Since the morphology of two-phase systems affects the mechanical properties of polymer hybrids, attempts have been made to improve the compatibility between PIs and silica by increasing interfacial interactions. Wang et al. [13, 14], Schrotter et al. [15] Chen and Iroh [16], Xenopoulos et al. [17], Musto et al. [18], and Chang et al. [19] have used different organosilanes with tetraalkoxysilane to produce silica network in the PI matrix. The organic groups present on these silanes, for example, aminophenyl-trimethoxysilane, aminopropyltrimethoxysilane, diaminophenyltetramethyl-disiloxane, glycidyloxy-propyltrimethoxysilane, aminopropylmethyl-diethoxysilane, and diaminopropyltetramethyl-disiloxane, are supposed to interact with organic PAA chain and alkoxy groups during the sol-gel process become the part of the silica network.

Present authors $[20,21]$ have found that the introduction of hydroxyl groups on the backbone of polymer chain can have a positive effect through physical or chemical 
interactions between organic and inorganic components. The morphology of silica particle produced in such matrices is totally different and particle size is much smaller for the same silica contents as compared to simple matrix without hydroxyl groups and this has a positive influence on the thermal and mechanical properties of the resulting hybrids.

The reaction of hydroxyl groups on the polymer chain, however, is very slow with the alkoxy groups of TEOS and in the sol-gel process usually a physical bonding between the matrix and the silica network can be achieved. Also the $\mathrm{Si}-\mathrm{O}-\mathrm{C}$ bonds formed by the reaction of hydroxyl groups on the polymer chain and the alkoxy groups from the silane during the sol-gel process are considered very weak. In the present work, the PAA chains containing pendant hydroxyl groups synthesized from the reaction of pyromellitic dianhydride (PMDA) with a mixture of oxydianiline (ODA) and 2,4-diminophenol (2,4-DAP) were reacted with isocyanatopropyltriethoxysilane (ICTEOS) to produce pendant alkoxy groups on the chain. The number of pendant alkoxy groups on PAA chain could be varied by changing the proportion of 2,4-DAP in the total diamine content in the reaction mixture. The reaction of isocyanato group with the $-\mathrm{OH}$ group leading to a polyurethane linkage is considered as very fast. On addition of an appropriate amount of TEOS, the sol-gel process was carried out to produce an extensively bonded silica network in the matrix. Phase compatabilization to reduce the agglomeration tendencies in the inorganic phase is thus achieved by chemical reaction between the matrix having alkoxy groups and those of TEOS. The PAA with no hydroxyl groups on the chain was prepared by the reaction of a mixture of 1,3-phenylenediamine (1,3-DAB) and oxydianiline (ODA) in dimethylacetamide (DMAc) with equimolar amount of pyromellitic dianhydride (PMDA) and this acts as control system. The resulting hybrid films in both cases were imidized. The morphology, thermal stability, visco-elastic and thermal mechanical properties of the PI-silica hybrid films were studied and related with the amount of silica and the extent of chemical bonding between the organic and inorganic phases.

\section{EXPERIMENTAL}

\subsection{Materials}

The monomers used to synthesize the polyimide were pyromellitic dianhydride (PMDA), 4,4' -oxydianiline (ODA), 1,3diaminobenzene (1,3-DAB). These monomers and tetraethoxysilane (TEOS), triethylamine (TEA), were of ananlytical grade obtained from Aldrich. The solvent anhydrous DMAc (water contents $\geq 0.05 \mathrm{wt} \%$ ) kept over molecular sieve was obtained from Aldrich. Diaminophenol-dihydrochloride (2, 4-DAP. $2 \mathrm{HCl}$ ) was obtained from Fluka and it was purified to remove $\mathrm{HCl}$ from the salt using TEA. The 2,4 DAP was copolymerized with ODA to produce PAA chain with hydroxyl groups. The isocyanatopropyltriethoxysilane (ICTEOS) 95\% pure used as coupling agent was obtained from ABCR Germany and used as such. All other chemicals and regents were of AR grade and used without further purification except 2,4-DAP. $2 \mathrm{HCl}$.

\subsection{Preparation of the hybrid films}

\subsubsection{Preparation of PAA solution}

For the preparation of PAA without pendant hydroxy groups on the chain, a mixture of ODA and $1,3-\mathrm{DAB},(0.025 \mathrm{~mol})$ in molar ratio $95: 5$; respectively, was placed into a 250 quickfit flask and dissolved by stirring in $170 \mathrm{~g}$ of anhydrous DMAc as solvent. PMDA, $(0.025 \mathrm{~mol})$ was added into it under complete anhydrous conditions. The viscosity increased quickly over the next one hour, and the reaction was allowed to proceed at room temperature for 24 hours to ensure a complete reaction.

\subsubsection{Preparation of the PAA solution with pendant alkoxy groups}

In order to prepare PAA with hydroxy groups on the chain, 1,3 -DAB was replaced with 2,4-DAP in the PAA synthesis. As only the salt of this compound was available, it was purified as follows: in a $100 \mathrm{ml}$ glass bottle, $0.254 \mathrm{~g}$ of $2,4-\mathrm{DAP} \cdot 2 \mathrm{HCl}$ (1.25 milli mol) was taken. Stoichiometric amount of TEA was added to neutralize $\mathrm{HCl}$ completely. About $10 \mathrm{~g}$ DMAc was then added to the mixture. The mixture was stirred for few minutes and finally filtered under vacuum to remove the precipitates of triethyl ammonium hydrochloride. To this solution of 2,4-DAP, $4.853 \mathrm{~g}$ of ODA (23.75 milli mol) and $160 \mathrm{~g}$ of solvent were added and stirred thoroughly for complete dissolution. An equimolar amount of PMDA (5.622 g, $0.025 \mathrm{~mol}$ ) was added to react with the diamines. The reaction mixture was stirred for additional 24 hours to ensure complete reaction. The inherent viscosities of the PI solutions at $25^{\circ} \mathrm{C}$ were in the range $2.1-2.33 \mathrm{dL} / \mathrm{g}$. Two types of PAA solutions were prepared, one with 5 and other with 10 mole percent of hydroxy amine. The coupling agent ICTEOS was added to the prepared PAA solutions in equimolar amount with 2,4-DAP, that is $5 \%$ ( or in double amount $10 \%$ ) by mol and the mixture was stirred at $50^{\circ} \mathrm{C}$ for 2 hours.

\subsubsection{Sol-gel processing and imidization reaction}

Silica network was produced in the above polymer solutions by carrying out the sol-gel process. A measured amount of TEOS was added to the polymer precursor solution with continued stirring until the solution became homogenous. A stoichiometric amount of water as $10 \mathrm{wt} \% 0.1 \mathrm{~N} \mathrm{HCl}$ solution in DMAc was then added. The stirring continued for 4 hours at $60^{\circ} \mathrm{C}$. Hybrids with various silica contents ranging from $5-40 \mathrm{wt} \%$ were prepared and the films (thickness varying from 0.08 to $0.10 \mathrm{~mm}$ ) were cast by solvent elution at $70^{\circ} \mathrm{C}$. These hybrid films were heated for 1 hours at $100^{\circ} \mathrm{C}$, 1 hours at $200^{\circ} \mathrm{C}, 0.5$ hours at $270^{\circ} \mathrm{C}$, and 1 hours at $300^{\circ} \mathrm{C}$ in sequence to carry out the imidization process [12]. The silica network formation simultaneously took place with the imidization process.

The hybrids from the PI matrix without hydroxyl groups are referred to as PISi-T and those with hydroxyl groups having 5\% 2,4-DAP mixed with $5 \%$ by mol ICTEOS as PISiP5-I-T while those hybrids containing 10\% 2,4-DAP mixed 


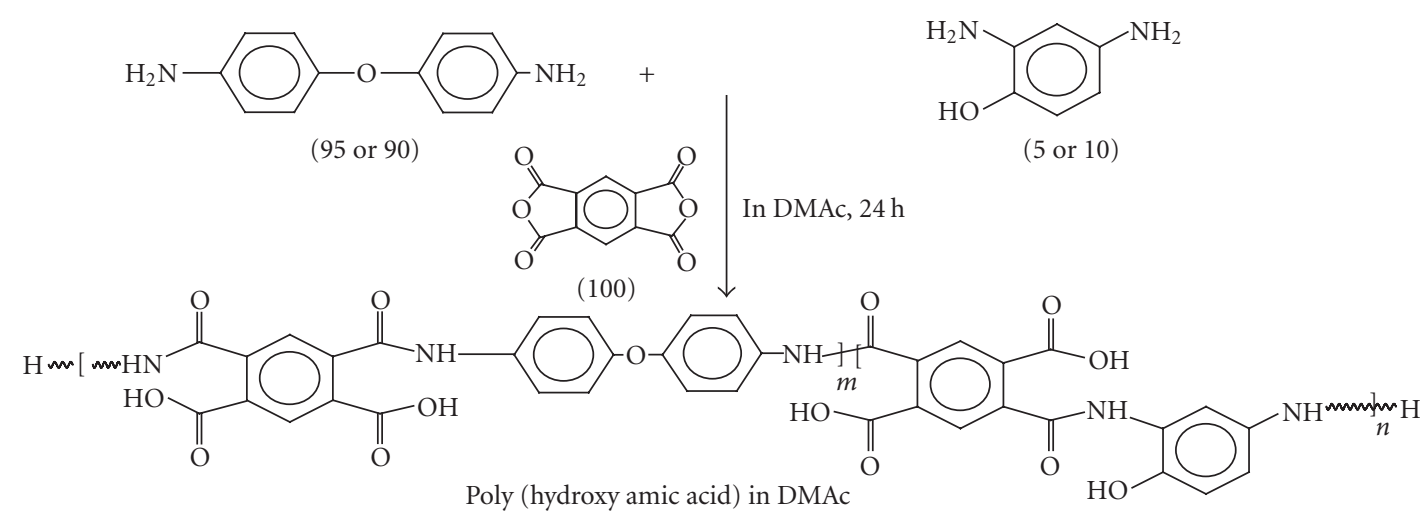

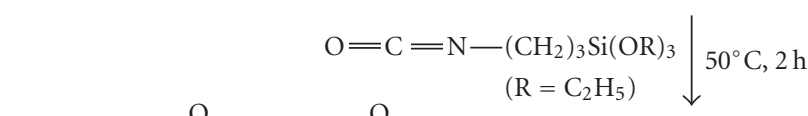

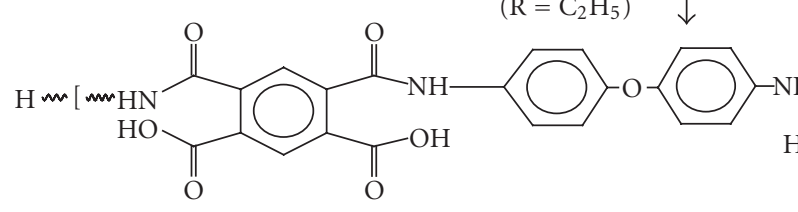<smiles>NC(=O)c1cc(C(=O)O)c(C(=O)O)cc1C(N)=O</smiles>

Poly(hydroxy amic acid) with ICTEOS

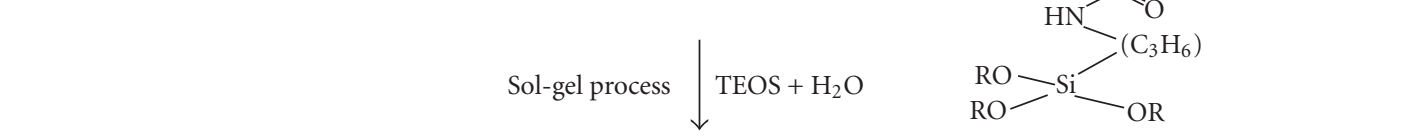<smiles>O=C(O)CCC(=O)Nc1ccc(Oc2ccc(NC(=O)c3cc(C(=O)N[In])c(C(=O)O)cc3C(=O)O)cc2)cc1</smiles><smiles>C[Si](C)(C)O[Si](C)(C)O[Si](C)(O)O[Si](C)(O)O[Si](C)(C)O</smiles>

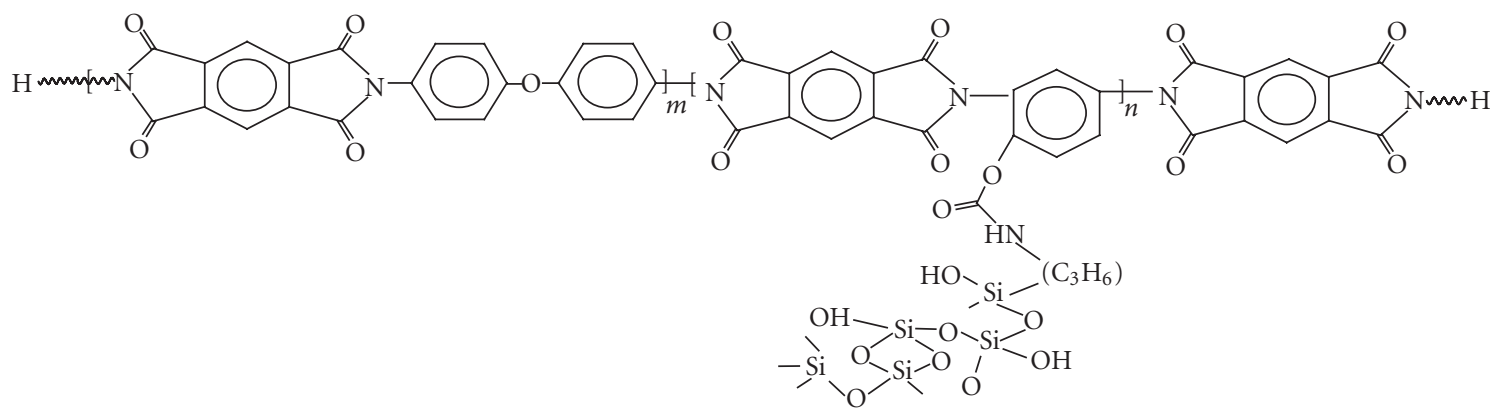

FIGURE 1: Synthesis of chemically bonded polyimide-silica hybrids.

with $10 \%$ by mol ICTEOS are referred to as PISi-P10-I-T. The flow sheet diagram describing the preparation of chemically bonded hybrids is given in Figure 1.

\subsection{Measurements}

The imidization process and the silica network formation in the hybrid films were monitored by the FTIR spectroscopy using a Perkin-Elmer FTIR 2000 spectrophotometer. FTIR analysis was also used to confirm the formation of chemical bonds between the organic matrix and the silica network. For scanning electron microscopy (SEM), the brittlefractured films were sputter coated with gold by means of Balzer's SCD-50 sputter coater and then examined by JSM630 Joel scanning electron microscope operated at $20 \mathrm{kV}$.

Dynamic mechanical analysis (DMA) was used to measure $\alpha$-relaxation temperature associated with the glass 
transition and the temperature variation of storage modulus of the hybrid material. These measurements were performed under tension mode in the temperature range $100-500^{\circ} \mathrm{C}$ at $5^{\circ} \mathrm{C} / \mathrm{min}$ ramp using a frequency of $5 \mathrm{~Hz}$ under inert atmosphere on a DMA Q-800 (TA, USA).

Thermal mechanical analysis to measure the linear coefficient of thermal expansion was performed on Schimadzu TMA-50 at a heating rate of $10^{\circ} \mathrm{C} / \mathrm{min}$ with an applied load of $4.00 \mathrm{~g}$ under nitrogen gas. Thermogravimetry (TG) was performed on approximately $10 \mathrm{mg}$ of the sample from ambient to $800^{\circ} \mathrm{C}$ at a heating rate of $10^{\circ} \mathrm{C} / \mathrm{min}$ in a dynamic synthetic air atmosphere $(30 \mathrm{ml} / \mathrm{min})$, using TGA-50 Shimadzu automatic analyzer.

\section{RESULTS AND DISCUSSION}

The solutions of the polyamic acid-silica mixtures after the sol-gel process and prior to the film casting were homogeneous in all cases. In the case of PISi-T system, the hybrids films up to $10 \mathrm{wt} \%$ silica were transparent and brownish yellow, and those with more than $20 \%$ silica were opaque and dark brown in color. In the case of PISi-P5-I-T and PISi-P10I-T hybrids, films up to $20 \mathrm{wt} \%$ silica loading were transparent and dark brown in color. Those with 30-40 wt\% silica were semi-transparent and dark brown in color. The optical transparency of the films thus increased as the chemical interaction between the phases reduced the tendency of silica particle to agglomerate. The hybrid films remain transparent so far as the size of these particles is less than the wavelength of light and become opaque when their size increases.

\subsection{FTIR spectroscopy}

The curing of PAA to PI and the reaction of the pendant hydroxyl groups with the ICTEOS were monitored by FTIR spectroscopy. In case of PAA, the broad band around 1660 $\mathrm{cm}^{-1}$, called amide I mode, involves contributions from $\mathrm{C}=\mathrm{O}$ stretching, $\mathrm{C}-\mathrm{N}$ stretching, and $\mathrm{C}-\mathrm{N}-\mathrm{C}$ deformation vibrations. A band at $1570-1540 \mathrm{~cm}^{-1}$, known as amide II mode, is a mixed contribution of $\mathrm{N}-\mathrm{H}$ in plane bending, the $\mathrm{C}-\mathrm{N}$ stretching, and $\mathrm{C}-\mathrm{C}$ stretching vibrations. The amide $\mathrm{I}$ and amide II disappeared entirely after the thermal imidization, and new strong absorption bands at 1777-1782, 17221730 , and $1377-1380 \mathrm{~cm}^{-1}$ due to the asymmetric stretching of $\mathrm{C}=\mathrm{O}$, symmetric stretching of $\mathrm{C}=\mathrm{O}$, and symmetric stretching of $\mathrm{C}-\mathrm{N}$, respectively, which are assigned to the imide ring [22]. Appearance of these characteristic absorption bands confirms the curing of PAA to PI. The appearance of absorption peaks at 1100 and $830 \mathrm{~cm}^{-1}$ in the IR spectra of PISi-P10-IT and PISi-T meant the formation of siliconoxygen bonds, that is, the silica network. The FTIR absorption spectra have been explained elsewhere [23] and details are not provided in the present work.

In order to find whether the ICTEOS reacted with the hydroxyl groups on PAA, we subtracted the absorption spectrum obtained after imidization in case of films where ICTEOS was added to hydroxy PAA film (PI-P10-I) from the hydroxy PAA film (PI-P10). This spectrum is shown in

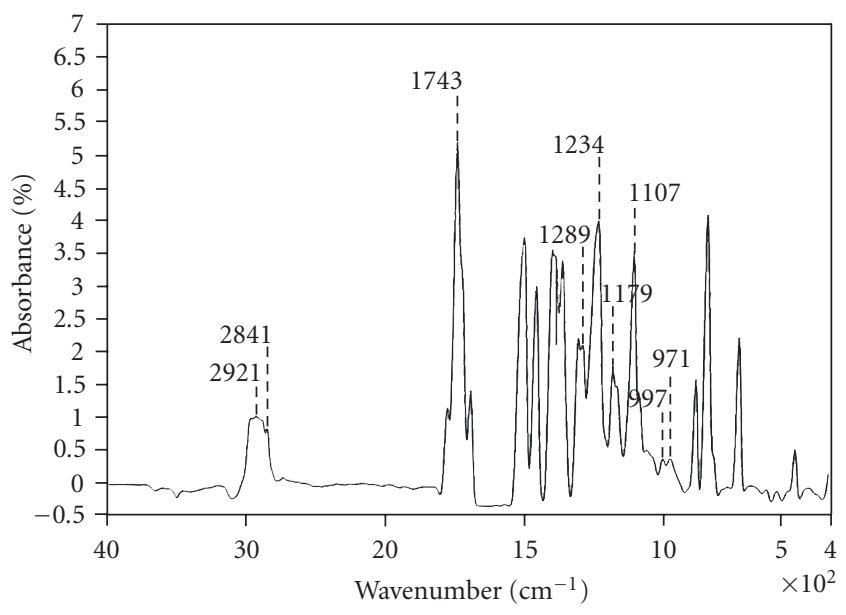

FIGURE 2: Normalized FTIR spectrum showing the absorption due to chemical linkages from ICTEOS with the matrix.

Figure 2. The absence of absorption in the region $2250 \mathrm{~cm}^{-1}$ due to isocyanto groups and appearance of urethane linkage at $1743 \mathrm{~cm}^{-1}$ show that ICTEOS has reacted (see Figure 1) with the pendant hydroxyl groups on the polymer chain. The absorption in the region $2840-2920 \mathrm{~cm}^{-1}$ and at $1234 \mathrm{~cm}^{-1}$ due to $-\mathrm{CH}_{2}-\mathrm{CH}_{2}-$ linkage and $\mathrm{Si}-\mathrm{C}$ bonds, respectively, further confirms that ICTEOS has become the part of polymer chain. The presence of small peaks at $1179 \mathrm{~cm}^{-1}$ and at $971 \mathrm{~cm}^{-1}$ shows the presence of $\mathrm{Si}-\mathrm{O}-\mathrm{R}$ linkages, that is, the alkoxy groups of the ICTEOS. As the sol-gel process was not carried out with these experimental systems, purely made for FTIR analysis, so these groups remain partially unhydrolyzed/uncondensed in the matrix. The above results clearly show the successful binding of ICTEOS on the polymer chain which could further link the silica network with the matrix.

\subsection{Morphological studies}

The scanning electron micrographs showing the effect of silica loading and reinforcement binding with matrix on the morphology of the resulting hybrids are given in Figure 3. The micrographs in Figures 3(a) and 3(b) show the morphology of the unbonded hybrids with 20 and $40 \mathrm{wt} \%$ of silica, respectively, in the matrix. The silica particles are seen as white beads with round or oval shape and sharp boundaries. The average diameter of the particles increased from 0.2 to 8 micrometers as the silica contents were increased from 5 to $40 \mathrm{wt} \%$. The sharp, clear boundaries of the silica particles with some interfacial spaces show that the pure organic and inorganic phases had poor interaction and as the silica loading increased the tendency towards phase separation increased. The micrographs in Figures 3(c) and 3(d) show the morphology of the PISi-P5-I-T hybrids with 20 and $40 \mathrm{wt} \%$ silica loading, respectively, in the matrix. Though with increased silica loading, the tendency of the particle size to increase remains there, however, there was a considerable 


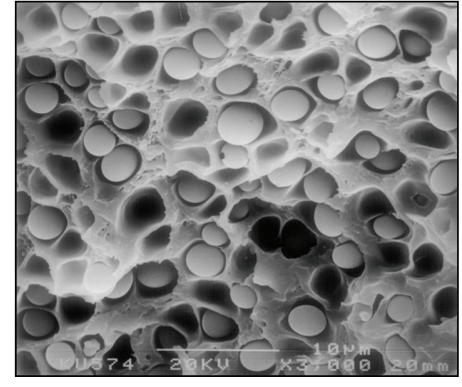

(a)

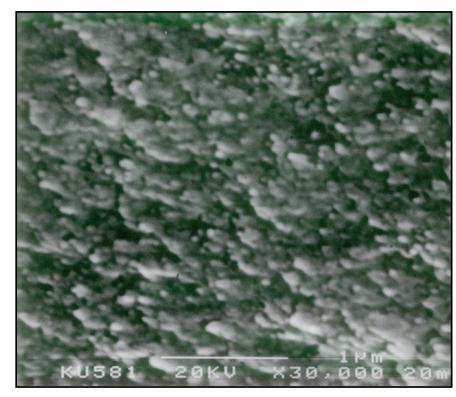

(c)

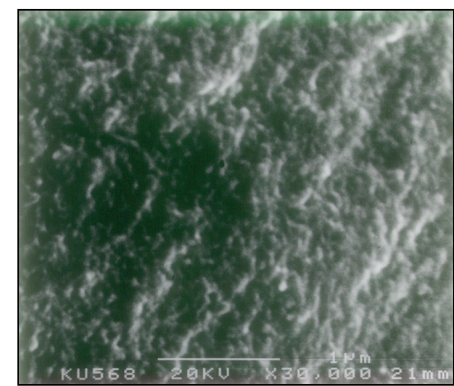

(e)

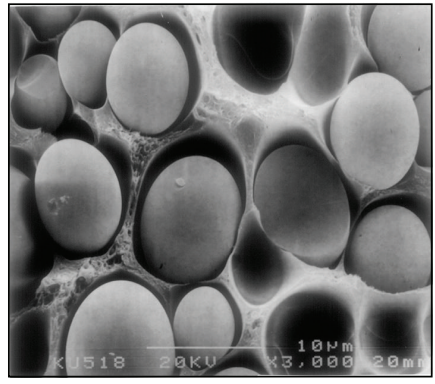

(b)

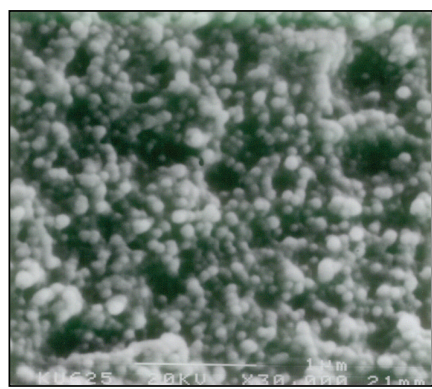

(d)

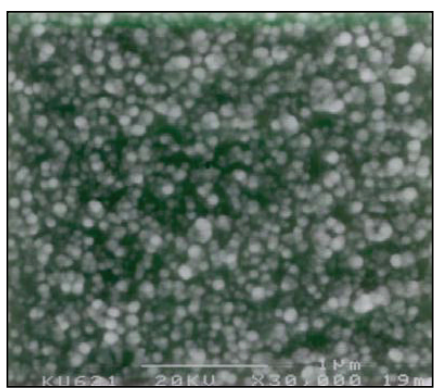

(f)

FIGURe 3: Scanning electron micrographs for the polyimide silica hybrids with $20 \mathrm{wt} \%$ silica loading; (a) PISi-T, (c) PISi-P5-I-T, (e) PISiP10-I-T 40 wt\% silica loading; (b) PISi-T, (d) PISi-P5-I-T, (f) PISi-P10-I-T.

decrease in the particle size as compared to the unbonded hybrids. The diameter of the silica particles varied from $10 \mathrm{~nm}$ to $200 \mathrm{~nm}$ in these hybrids for silica loading varying from 5 to $40 \mathrm{wt} \%$, respectively. The bonded hybrid system displayed a more adhesive interface between enforcement and the matrix thus leading to a homogenous distribution of silica particles and retarding their phase separation from the matrix. The micrographs in Figures 3(e) and 3(f) show the morphology of PISi-P10-I-T hybrids. As seen from these graphs, the increased extent of binding between the phases has further reduced the particle diameter which varies from $5-100 \mathrm{~nm}$ for the similar silica loading as stated above. The presence of alkoxy groups on the PI matrix and their co-condensation with TEOS to produce silica network during the sol-gel process has retarded the tendency of silica network to agglomerate into large particles thus reducing their size to nanolevel and making the distribution of the inorganic network more homogenous. The finer silica particles in the matrix with enhanced adhesion between the phases which improved the transparency of the hybrid films can also have great influence on the thermal mechanical properties of the hybrid material.

\subsection{Visco-elastic properties}

The temperature variation of storage modulus $\left(\mathrm{E}^{\prime}\right)$ and $\tan \delta$ (where $\tan \delta$ is the loss factor related to the ratio of loss modulus to storage modulus) for the three hybrid systems studied is shown in Figures 4-6. The visco-elastic data have been given in Table 1. Incorporating silica in the matrix increased the storage modulus and high temperature reliability of the PI. Table 1 gives the values of storage modulus for different silica contents at two different temperatures for the studied hybrid systems. The increase in the modulus values as compared to the pure polymer is more in case of bonded hybrids. 


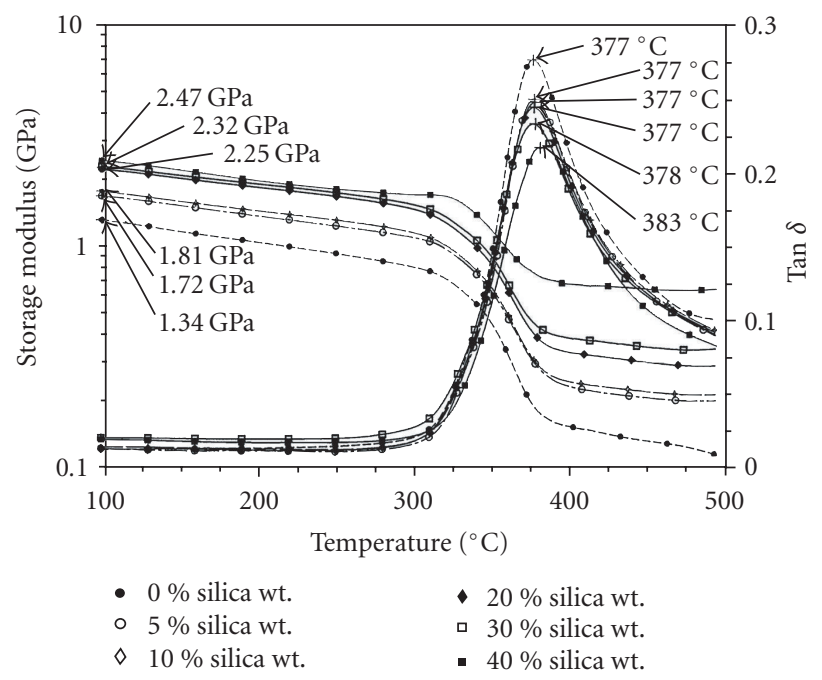

FIgURE 4: Temperature dependence of storage modulus and tan delta for the PISi-T hybrids; silica wt\%: $0(\bullet), 5(\circ), 10(\diamond), 20(\diamond)$, $30(\square), 40(\square)$.

It also depends on the degree of interphase bonding and the values obtained are higher in PISi-P10-I-T hybrids as compared to PISi-P5-I-T system (Table 1). As the temperature is increased, the modulus drops to about an order of magnitude in the rubbery region in case of pure PI. The modulus decreases linearly with temperature up to about $340^{\circ} \mathrm{C}$ and at $T_{g}$ a rapid decrease in $E^{\prime}$ is witnessed. The hybrid samples with different silica contents all have higher $\mathrm{E}^{\prime}$ values in the rubbery region as compared to the pure PI. The rate of decrease of $\mathrm{E}^{\prime}$, however, is considerably lower with large silica loading. The chemically bonded hybrids tend to retain the modulus values at higher temperature above $425^{\circ} \mathrm{C}$ than as compared to the unbonded system (Table 1).

The magnitude of the $\tan \delta$ curves decreases with increasing the amount of silica (Figures 4-6). This suggests that the mobility of the polymer chains is restricted due to presence of silica in the matrix and the material show more elastic behavior as the tendency to viscous flow behavior is reduced. A comparison of the variation of $\tan \delta$ with temperature for the unbonded and bonded hybrids shows that the bonded hybrids have much lower values of $\tan \delta$ for the similar silica loading. The $\mathrm{T}_{\mathrm{g}}$ associated with $\alpha$-relaxation measured from the maxima of the $\tan \delta$ curve (Table 1) for the unbonded hybrids with $40 \mathrm{wt} \%$ silica shows an increase of $5^{\circ} \mathrm{C}$ from the pure PI (Figure 4). The peak temperature of $\tan \delta$ is shifted slightly to higher temperature with increasing silica. On the other hand, for the PISi-P5-I-T hybrids an increase of about $22^{\circ} \mathrm{C}$ in the $\mathrm{T}_{\mathrm{g}}$ was observed with increasing silica contents from zero to $40 \mathrm{wt} \%$. As the number of hydroxyl groups on the PI chains was increased, the $\mathrm{T}_{\mathrm{g}}$ of the pure matrix was also shifted to the higher temperature. This is due to intermolecular bonding of the polymer chain due to presence of polar groups. The $T_{g}$ recorded for the pure polymer used in case of PISI-P10-I-T hybrids was $403^{\circ} \mathrm{C}$. The maximum value of $422^{\circ} \mathrm{C}$ was recorded in this case with $40 \%$ silica in-

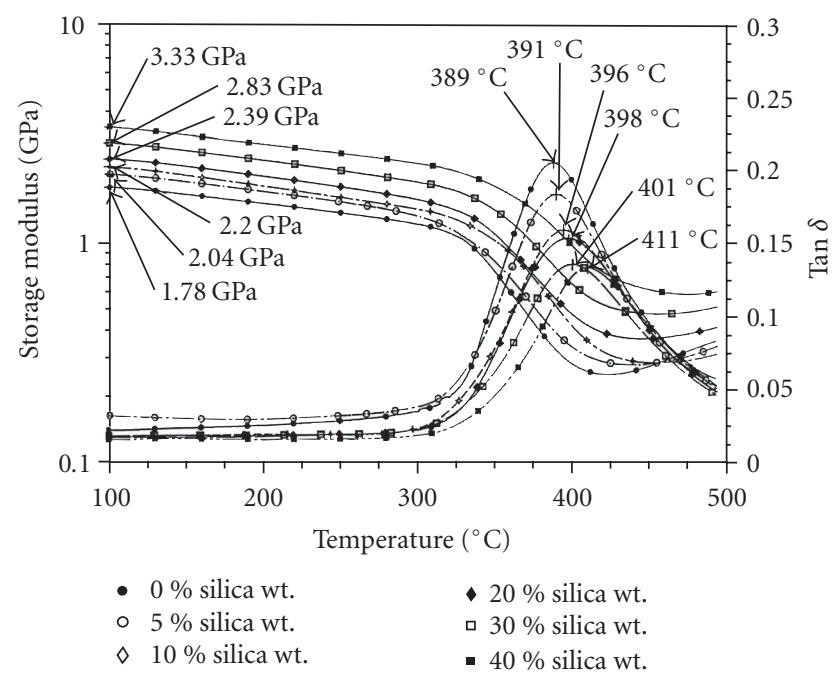

FIgURE 5: Temperature dependence of storage modulus and tan delta for the PISi-P5-I-T hybrids; silica wt\%: $0(\bullet), 5(\circ), 10(\diamond)$, $20(\checkmark), 30(\square), 40(\mathbf{\square})$.

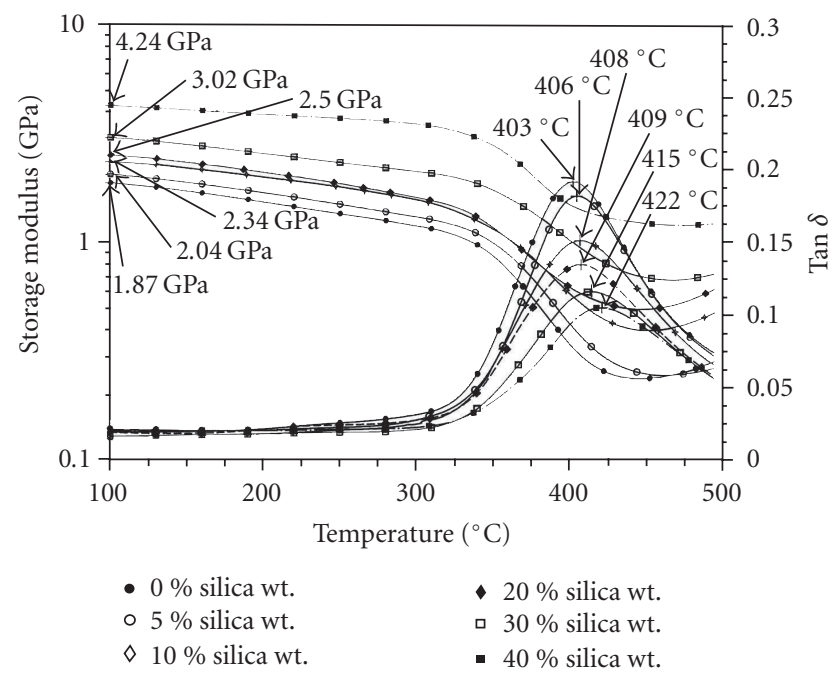

FIgURE 6: Temperature dependence of storage modulus and tan delta for the PISi-P10-I-T hybrids; silica wt\%: $0(\bullet), 5(\circ), 10(\diamond)$, $20(\diamond), 30(\square), 40(\mathbf{\square})$.

clusion in the matrix (Figure 6). The large reduction in the $\tan \delta$ curves and increase in $\mathrm{T}_{\mathrm{g}}$ (Figure 7) for these hybrids can be attributed to the strong interaction/presence of covalent bonding between PI and silica. The Interfacial interaction also reduces the tendency of network structure to agglomerate into large silica particles which are reduced to almost nanolevel. These particles have high surface to volume ratio. More surface area available to bond/absorb the polymer chains for given silica content make the polymer chains stiffer. This also explains why the bonded hybrids with finer morphology had higher modulus values than that of the unbonded hybrids for the similar silica loading. 
TABLE 1: Viscoelastic properties of polyimide-silica hybrids.

\begin{tabular}{|c|c|c|c|c|c|c|c|c|c|c|c|c|}
\hline \multirow{2}{*}{$\mathrm{SiO}_{2}(\mathrm{wt} \%)$} & \multicolumn{3}{|c|}{$\begin{array}{l}\text { Storage modulus } \\
(\mathrm{GPa}) \text { at } 100^{\circ} \mathrm{C}\end{array}$} & \multicolumn{3}{|c|}{$\begin{array}{l}\text { Storage modulus } \\
\text { at } 425^{\circ} \mathrm{C}\end{array}$} & \multicolumn{3}{|c|}{$\mathrm{T}_{\mathrm{g}}\left({ }^{\circ} \mathrm{C}\right)$} & \multicolumn{3}{|c|}{ Tan delta $(\delta)$} \\
\hline & PISi & $\begin{array}{l}\text { PISi- } \\
\text { P5-I-T }\end{array}$ & $\begin{array}{l}\text { PISi- } \\
\text { P10-I-T }\end{array}$ & PISi & $\begin{array}{l}\text { PISi- } \\
\text { P5-I-T }\end{array}$ & $\begin{array}{l}\text { PISi- } \\
\text { P10-I-T }\end{array}$ & PISi & $\begin{array}{l}\text { PISi- } \\
\text { P5-I-T }\end{array}$ & $\begin{array}{l}\text { PISi- } \\
\text { P10-I-T }\end{array}$ & PISi & $\begin{array}{l}\text { PISi- } \\
\text { P5-I-T }\end{array}$ & $\begin{array}{l}\text { PISi- } \\
\text { P10-I-T }\end{array}$ \\
\hline 0 & 1.34 & 1.83 & 1.87 & 0.13 & 0.25 & 0.25 & 376.60 & 388.98 & 403.29 & 0.28 & 0.21 & 0.19 \\
\hline 5 & 1.72 & 2.04 & 2.04 & 0.20 & 0.28 & 0.29 & 377.38 & 390.64 & 405.09 & 0.25 & 0.18 & 0.16 \\
\hline 10 & 1.81 & 2.20 & 2.34 & 0.23 & 0.31 & 0.43 & 377.77 & 395.52 & 407.80 & 0.25 & 0.16 & 0.15 \\
\hline 20 & 2.25 & 2.39 & 2.50 & 0.31 & 0.38 & 0.51 & 377.28 & 398.17 & 408.51 & 0.25 & 0.15 & 0.13 \\
\hline 30 & 2.32 & 2.83 & 3.02 & 0.32 & 0.51 & 0.78 & 378.16 & 401.41 & 415.46 & 0.23 & 0.13 & 0.11 \\
\hline 40 & 2.48 & 3.33 & 4.24 & 0.33 & 0.72 & 1.28 & 383.45 & 411.47 & 422.15 & 0.23 & 0.13 & 0.10 \\
\hline
\end{tabular}

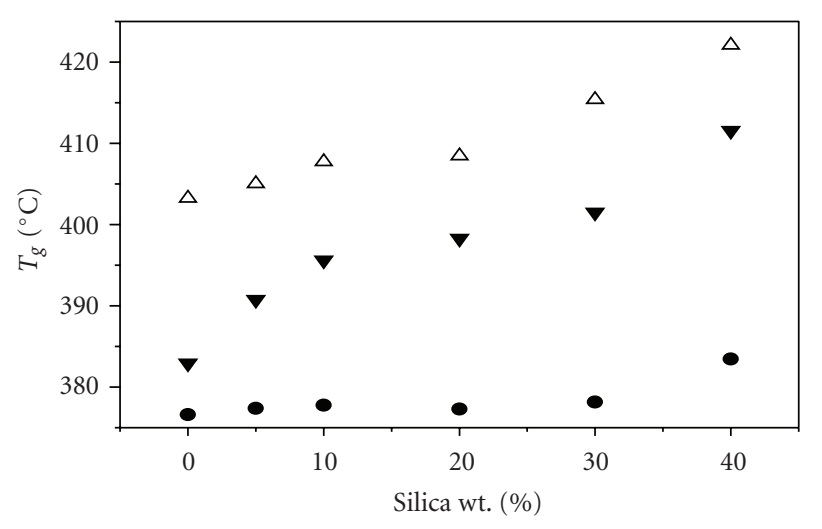

- PISi-T

$\nabla$ PISi-P5-I-T

$\triangle$ PISi-P10-I-T

Figure 7: Variation of glass transition with silica content in polyimide-silica hybrids: PISi-T (•), PISi-P5-I-T ( $)$, PISi-P10-I-T $(\triangle)$.

\subsection{Thermal mechanical analysis}

Figure 8 shows linear thermal expansion for pure PI, hydroxy PI and the chemically bonded PI-silica hybrids as function of temperature. The value of coefficient of thermal expansion for the pure PI is $52.1 \mathrm{ppm} /{ }^{\circ} \mathrm{C}$ at $50^{\circ} \mathrm{C}$. The average value in the temperature range of $50-300^{\circ} \mathrm{C}$ was measured as $61.42 \mathrm{ppm} /{ }^{\circ} \mathrm{C}$. Beyond this temperature softening of the polymer chain may be taking place. Our value is in agreement with the values of $55 \mathrm{ppm} /{ }^{\circ} \mathrm{C}$ reported by Yano et al. [24] at $150^{\circ} \mathrm{C}$ and $48.5 \mathrm{ppm} /{ }^{\circ} \mathrm{C}$ reported by Southward et al. [25] at $50^{\circ} \mathrm{C}$. The reduction in the CTE value of PI was observed with the introduction of hydroxyl groups on the chain and the average value for the hydroxyl PI was $56.88 \mathrm{ppm} /{ }^{\circ} \mathrm{C}$. In case of hybrid film PISi-P5-I-T with $40 \mathrm{wt} \%$ silica, the $\mathrm{CTE}$ values were reduced to $24.03 \mathrm{ppm} /{ }^{\circ} \mathrm{C}$. Also the softening point is increased to higher temperature. The CTE of hybrid materials is dependent upon matrix, type of reinforcement, and volume fraction of the reinforcement and interaction between the phases. In case of PiSi-P10-I-T hybrids where there is more bonding between the matrix and the silica network, the average CTE value recorded was $20.46 \mathrm{ppm} /{ }^{\circ} \mathrm{C}$. PIs are

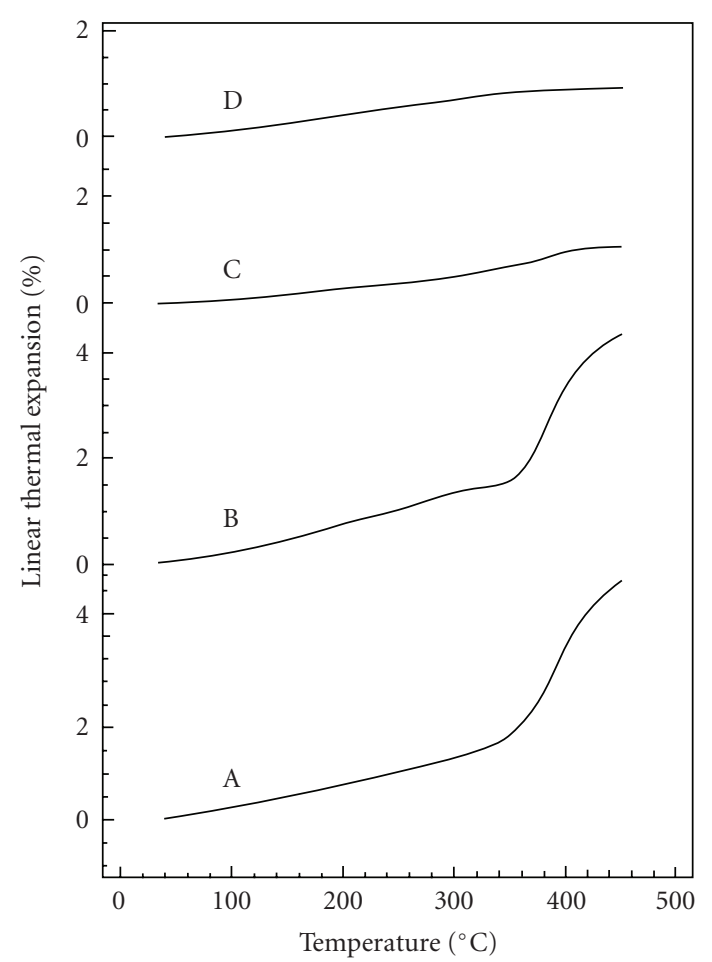

FIGURE 8: Variation of linear thermal expansion with temperature for (A) polyimide, (B) hydroxy-polyimide, (C) PISi-P5-I-T hybrids with $40 \mathrm{wt} \%$ silica, (D) PISi-P10-I-T hybrids with $40 \mathrm{wt} \%$ silica.

commonly used in microelectronic industry as interlayer dielectrics for thin film wiring in multichip packages. To meet the stringent demands of industry, the material properties such as CTE has to be controlled precisely. Most of the low dielectric PIs have undesirable high values of CTE which may result in fatal damage from thermal stresses generated due to the mismatch between the semiconductor chip and insulating PI. Such hybrids material therefore can be extremely useful in such applications requiring a controlled CTE.

\subsection{Thermal stability}

The TGA thermograms of the three hybrid systems, PISi-T, PISi-P5-I-T, and PISi-P10-I-T with various silica contents, 


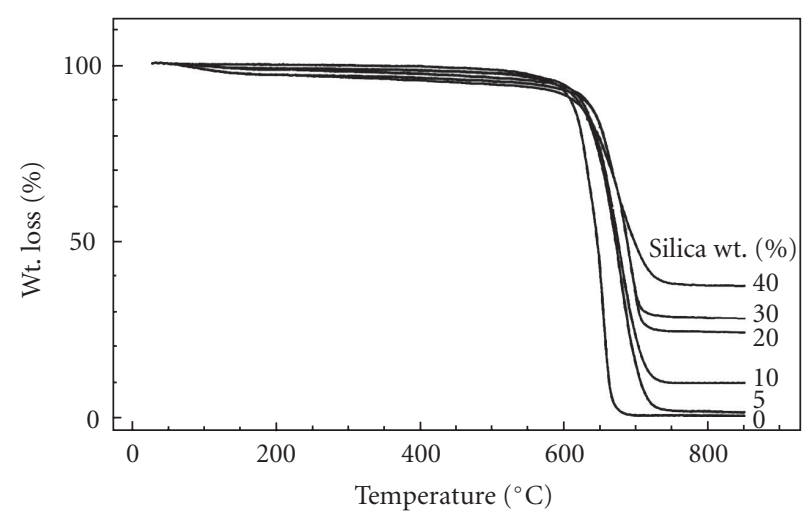

FIgURE 9: TGA thermograms for the PISi-T hybrids with various silica contents.

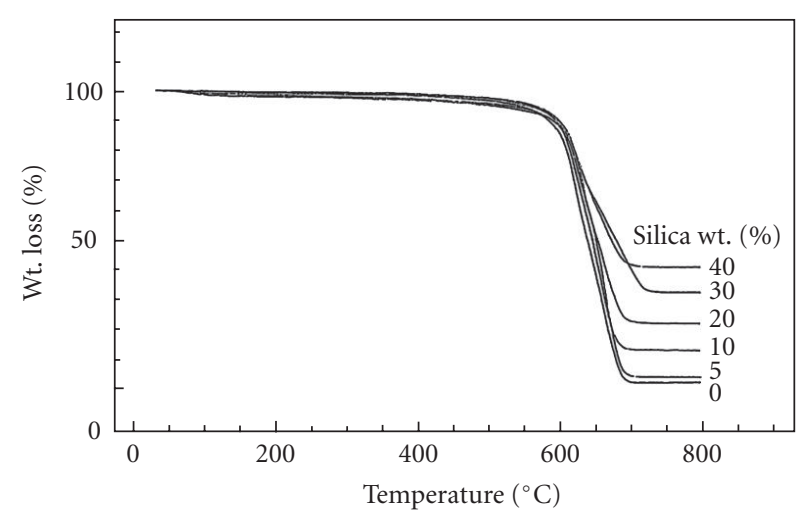

FIGURE 10: TGA thermograms for the PISi-P5-I-T hybrids with various silica contents.

are shown, respectively, in Figures 9, 10, and 11. The decomposition temperature of the pure PI was around $650^{\circ} \mathrm{C}$. Slight decrease in the weight at lower temperature for the hybrids could be due to the loss of by-products $\left(\mathrm{H}_{2} \mathrm{O}, \mathrm{EtOH}\right)$ from the condensation reaction of the silica network. The hydroxy PI used for preparing the bonded hybrids show slightly higher thermal decomposition temperature than the PI used for the unbonded hybrids. It seems that the presence $\mathrm{OH}$ groups on the polymer chain act as free radical quencher during the oxidative degradation process. As the amount of silica is increased in the matrix, the thermal decomposition behavior shows a gradual weight loss with increasing temperature up to $770^{\circ} \mathrm{C}$. The effect is more pronounced in the hybrids where higher silica loading have been used in the matrix. Since the formed silica network exhibits good thermal stability even at $800^{\circ} \mathrm{C}$, the weight loss of the hybrids is resulting mainly from the PI matrices. It seems that the polymer chains absorbed or trapped in the network are protected from thermo-oxidative process and this hinders the process of degradation. The PI hybrids therefore show slightly better thermal stability as compared to the matrix. The weight retained above $770^{\circ} \mathrm{C}$ in all the hybrids was found proportional

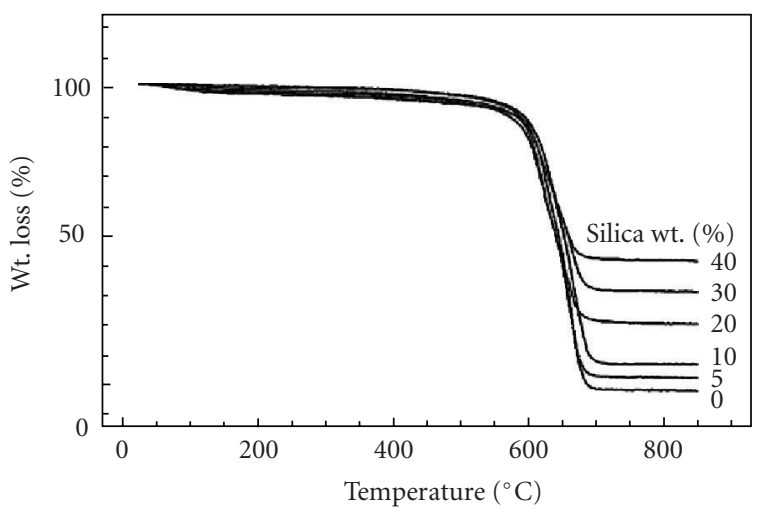

FIgURE 11: TGA thermograms for the PISi-P10-I-T hybrids with various silica contents.

to the silica contents used in the matrix, meaning thereby that the sol-gel process was carried out almost completely in the present studies.

\section{CONCLUSIONS}

The present studies on PI-Silica hybrids show that interphase chemical links between the silica network and the polymer chain prevent the agglomeration of silica particles, reduce the particle size to nanolevel thus making their distribution more homogenous in the matrix. The improved interfacial interaction between the phases enhances the mechanical strength particularly at high temperatures. The glass transition temperature of the polymer is increased more with addition of silica in these systems as compared to the one where no bonding exists between the phases. The values of coefficient thermal expansion are greatly reduced and thermal stability of the material is enhanced. Chemically bonded polyimidesilica nanocomposites thus show better mechanical and thermal properties.

\section{ACKNOWLEDGMENTS}

The authors express their appreciation to the Faculty of Graduate Studies, Kuwait University (KU) for providing financial support. The authors acknowledge the Research Administration of KU for the grant under Project SC 07/01. The technical support from the EM unit (Project GS 03/01) and the general facilities Project 01/01 under SAF program is also appreciated.

\section{REFERENCES}

[1] M. Biswas and S. S. Ray, "Recent progress in synthesis and evaluation of polymer-montmorrillonite nanocomposites," in New Polymerization Techniques and Synthetic Methodologies, vol. 155 of Advances in Polymer Science, pp. 167-221, Springer, Berlin, Germany, 2001.

[2] D. Schmidt, D. Shah, and E. P. Giannelis, "New advances in polymer/layered silicate nanocomposites," Current Opinion in Solid State and Materials Science, vol. 6, no. 3, pp. 205-212, 2002. 
[3] E. T. Thostenson, Z. Ren, and T.-W. Chou, "Advances in the science and technology of carbon nanotubes and their composites: a review," Composites Science and Technology, vol. 61, no. 13, pp. 1899-1912, 2001.

[4] A. K.-T. Lau and D. Hui, "The revolutionary creation of new advanced materials_carbon nanotube composites," Composites Part B: Engineering, vol. 33, no. 4, pp. 263-277, 2002.

[5] U. Schubert, N. Hüsing, and A. Lorenz, "Hybrid inorganicorganic materials by sol-gel processing of organofunctional metal alkoxides," Chemistry of Materials, vol. 7, no. 11, pp. 2010-2027, 1995.

[6] Z. L. Wang, Y. Liu, and Z. Zhang, Eds., Handbook of Nanophase and Nanostructured Materials Vol. 4: Materials Systems and Applications, Kluwer Academic/Plenum, New York, NY, USA, 2003.

[7] C. J. Brinker, Ed., Better Ceramics through Chemistry III, Materials Research Society, Warrendale, Pa, USA, 1988.

[8] C. J. Brinker and G. W. Scherer, Eds., Sol-Gel Science: The Physics and Chemistry of Sol-Gel Processing, Academic Press, New York, NY, USA, 1990.

[9] Z. Ahmad, "Ceramic-modified high temperature polymers," in The Encyclopedia of Materials; Science and Technology, K. H. J. Buschow, Ed., pp. 1086-1090, Elsevier Science, New York, NY, USA, 2001.

[10] Z. Ahmad and J. E. Mark, "Biomimetic materials: recent developments in organic-inorganic hybrids," Materials Science and Engineering C, vol. 6, no. 2-3, pp. 183-196, 1998.

[11] K. L. Mittel, Ed., Polyimides and Other High Temperature Polymers. Vol. 2, VSP, Leiden, The Netherlands, 2003.

[12] Z. Ahmad and J. E. Mark, "Polyimide-ceramic hybrid composites by the sol-gel route," Chemistry of Materials, vol. 13, no. 10 , pp. 3320-3330, 2001.

[13] S. Wang, Z. Ahmad, and J. E. Mark, "Polyimide-silica hybrid materials having interfacial bonding through use of a solgel technique," Macromolecular Reports, vol. A31, supplements 3\&4, pp. 411-419, 1994.

[14] S. Wang, Z. Ahmad, and J. E. Mark, "Polyimide-silica hybrid materials modified by incorporation of an organically substituted alkoxysilane," Chemistry of Materials, vol. 6, no. 7, pp. 943-946, 1994.

[15] J. C. Schrotter, M. Smaïhi, and C. Guizard, "Polyimide-siloxane hybrid materials: influence of coupling agents addition on microstructure and properties," Journal of Applied Polymer Science, vol. 61, no. 12, pp. 2137-2149, 1996.

[16] Y. Chen and J. O. Iroh, "Synthesis and characterization of polyimide/silica hybrid composites," Chemistry of Materials, vol. 11 , no. 5, pp. 1218-1222, 1999.

[17] C. Xenopoulos, L. Mascia, and S. J. Shaw, "Variables analysis in the gelation of alkoxysilane solutions for the production of polyimide-silica hybrids," Materials Science and Engineering C, vol. 6, no. 2-3, pp. 99-114, 1998.

[18] P. Musto, G. Ragosta, G. Scarinzi, and L. Mascia, "Polyimidesilica nanocomposites: spectroscopic, morphological and mechanical investigations," Polymer, vol. 45, no. 5, pp. 1697 1706, 2004.

[19] C.-C. Chang, K.-H. Wei, Y.-L. Chang, and W.-C. Chen, "Synthesis and optical properties of poly(BPDA-ODA)/silica hybrid thin films," Journal of Polymer Research, vol. 10, no. 1, pp. $1-6,2003$.

[20] A. Al Arbash, F. Al-Sagheer, A. A. M. Ali, and Z. Ahmad, "Thermal and mechanical properties of poly(hydroxy-imide)silica nanocomposites," International Journal of Polymeric Materials, vol. 55, no. 2, pp. 103-120, 2006.
[21] F. Al-Sagheer, A. A. M. Ali, S. Muslim, and Z. Ahmad, "Thermal and mechanical properties of chemically bonded aramidsilica nano-composites," Science and Technology of Advanced Materials, vol. 7, no. 1, pp. 111-118, 2006.

[22] C.-P. Yang and J.-H. Lin, "Syntheses and properties of aromatic polyamides and polyimides based on $N$-phenyl-3,3-bis[4( $p$-aminophenoxy)phenyl]phthalimidine," Journal of Polymer Science, Part A: Polymer Chemistry, vol. 32, no. 2, pp. 369-382, 1994.

[23] Sh. Al-Kandary, A. A. M. Ali, and Z. Ahmad, "Morphology and thermo-mechanical properties of compatibilized polyimide-silica nanocomposites," Journal of Applied Polymer Science, vol. 98, no. 6, pp. 2521-2531, 2005.

[24] K. Yano, A. Usuki, A. Okada, T. Kurauchi, and O. Kamigaito, "Synthesis and properties of polyimide-clay hybrid," Journal of Polymer Science, Part A: Polymer Chemistry, vol. 31, no. 10, pp. 2493-2498, 1993.

[25] R. E. Southward, D. S. Thompson, T. A. Thornton, D. W. Thompson, and A. K. St. Clair, "Enhancement of dimensional stability in soluble fluorinated polyimides via the in situ formation of lanthanum(III)-oxo-polyimide nanocomposites," Chemistry of Materials, vol. 10, no. 2, pp. 486-494, 1998. 

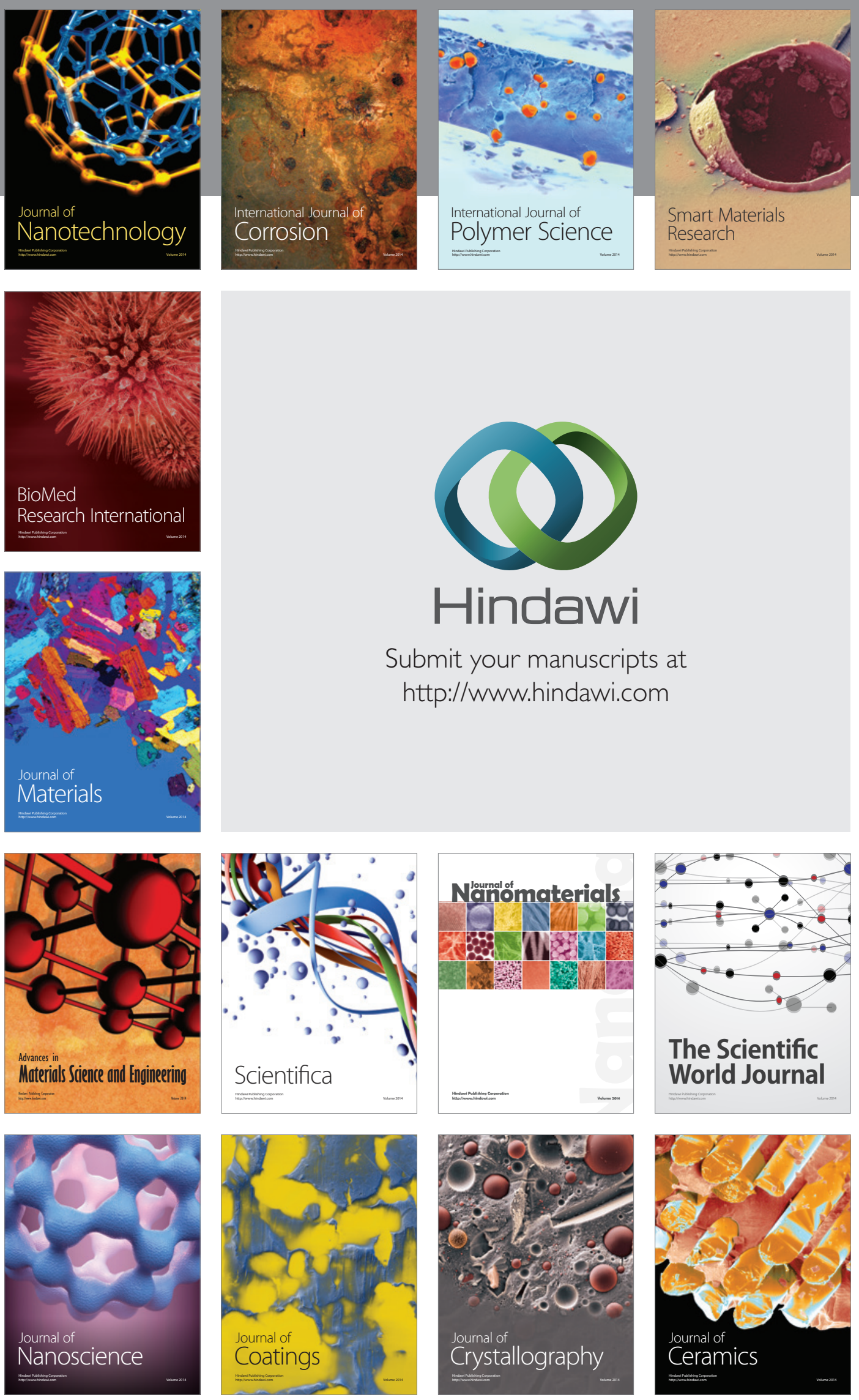

The Scientific World Journal

Submit your manuscripts at

http://www.hindawi.com

\section{World Journal}

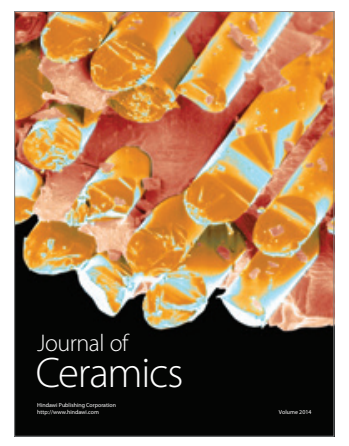

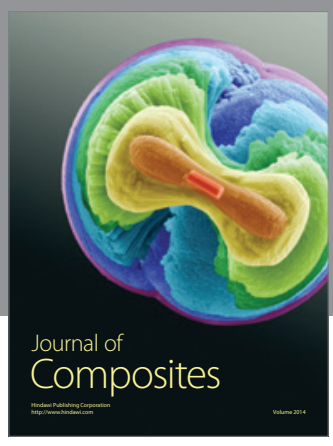
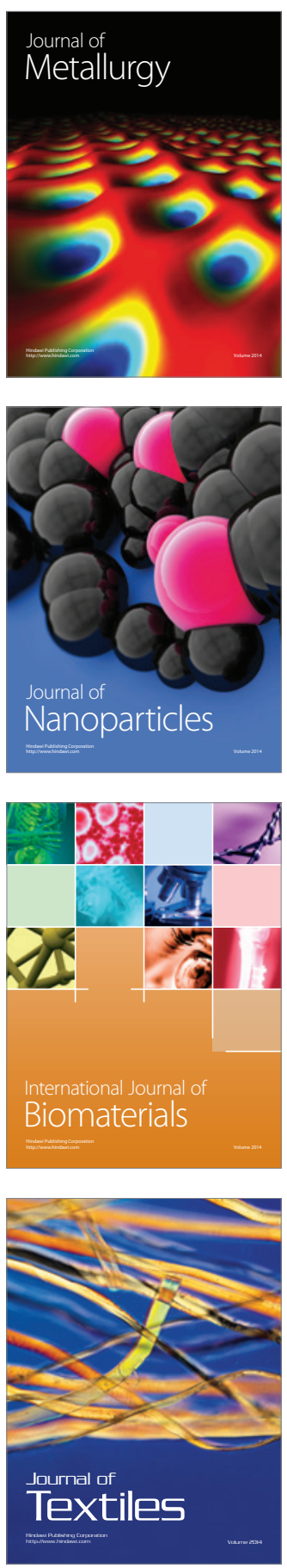